\title{
Huellas del Pasado. El uso de FuENTES y la FunCión DE REPRESENTANCIA EN LA REBELIÓN DE LAS CAÑADAS
}

\author{
Vladimir González Roblero
}

Resumen: El artículo a continuación discute la función de representancia o lugartenencia en el libro La rebelión de las Cañadas, de Carlos Tello Díaz comounade las modalidades de ficcióndela Historia que propone Paul Ricoeur. Se examina, entonces, el uso de fuentes orales y escritas en la re-construcción del pasado del EZZ LN hechapor el autor.

Palabras clave: Historiografía, ficción, construcción del pasado, fuentes, EZLN.

Enviado a dictamen: 29 de marzo de 2011

Aprobación: 27 de abril de 2011

Revisiones: 1

Vladimir González Roblero, doctor en Ciencias Sociales y Humanísticas por el Centro de Estudios Superiores de México y Centroamérica de la Universidad de Ciencias y Artes de Chiapas. Temas de especialización: historia contemporánea de Chiapas. Correo electrónico: vlatido@gmail.com.
Abstract: The article below discusses the role of lieutenancy in the book La rebelión de las Cañadas, by Carlos Tello Díaz one of the forms of fiction in historical writing proposed by Paul Ricoeur. It reviews, then, the use of oral and written sources in the reconstruction of the EZLN past made by the author.

Keywords: Historiography, fiction, construction of the past, sources, EZLN.

\section{Representancia o lugartenencia}

A 1 abordar el problema del pasado histórico, ${ }^{1}$ Paul Ricoeur se pregunta: "iqué significa el término 'real' aplicado al pasado histórico? ¿Qué podemos decir cuando decimos que algo ha sucedido 'realmente'?" (Ricoeur, 2006: 837). El cuestionamiento no está fuera de lugar en lo que se ha llamado filosofía posmoderna de la historia, en la que se cuestiona la realidad del pasado histórico. Dicha realidad, según su postura, no se puede conocer tal cual; solamente se hacen reconstrucciones de ella, o narraciones. ${ }^{2}$ Por lo tanto, en cuanto narración, el pasado no es unívoco. En este contexto, la pregunta de Paul Ricoeur es pertinente. El estatus ontológico del pasado responde, se define, a partir de las huellas que éste ha dejado. 
Ellas condicionan la realidad del pasado debido a que el historiador se atiene a los documentos o testimonios como prueba del haber-sido. Ricoeur alude a la noción de huella como vestigio del pasado:

La huella, en efecto, en cuanto es dejada por el pasado, vale por él: ejerce respecto a él una función de lugartenencia, de representancia (...) Esta función caracteriza la referencia indirecta, propia de un conocimiento por huella, y distingue de cualquier otro el modo referencial de la historia respecto al pasado. Por supuesto, este modo referencial es inseparable del trabajo de configuración: en efecto, nos formamos una idea inagotable del pasado gracias a una incesante rectificación de nuestras configuraciones. (Ricoeur, 2006: 838).

La relación del historiador con el pasado es indirecta, y el pasado mismo, entonces, en vez de ser representado es reconstruido a partir de las evidencias que valen por él. El proceso de reconstrucción, y no de representación, es el mismo que se ubica en lo que Ricoeur ha llamado mimesis II. Las reconstrucciones ambicionan acercarse al haber-sido, a lo que un día fue. Dicha ambición conduce a saber que lo narrado no es igual a lo sucedido. Las huellas, por otro lado, son las conexiones entre el tiempo vivido, es decir, lo que se ha prefigurado en la mimesis I, y el tiempo narrado, o mimesis II. La relación directa del historiador con el pasado, a través de las huellas que éste ha dejado, suponen entonces un cuasi pasado en tanto que lo narrado no es el pasado efectivo, el haber-sido, sino más bien lo que se piensa del pasado. Ricoeur diferencia, entonces, entre el conocimiento histórico y el pensamiento histórico (2006: 839).

El suponer que el pasado, en cuanto reconstrucción, es inagotable debido al proceso mimético configurador, nos lleva a pensar en la ficción como lo común entre los relatos historiográficos y los literarios. La configuración del haber-sido, a partir de las huellas del pasado sugiere, también, que la representancia del pasado se efectúa a partir del ver como el pasado. En este sentido vale decir, a partir de los entrecruzamientos de la ficción y la historia, que el relato historiográfico es cuasi ficción, pues en él operan pretensiones de verdad junto con operaciones ficcionalizantes. ${ }^{3}$

Dichas pretensiones de verdad, como se ha dicho, son las fuentes o huellas que anclan el relato con el habersido. El cuasi pasado en relatos con pretensiones de verdad se manifestará, en este tenor, gracias a las notas y citas a pie de página, así como a las explicitaciones de las fuentes, sean documentales u orales. En este sentido, en una investigación "autosuficiente", como sugiere llamar LaCapra a aquellas basadas en la evidencia (Morales, 2005: 443-490), el haber-sido se supeditará a las reconstrucciones posibles que sucedan en el nivel de la configuración. Dichas reconstrucciones no hacen más que llevar a pensar el pasado como ficción, es decir, que se construye. Aquí se alude a una sola dimensión del pasado, la referencial.

\section{Las huellas del pasado}

En La rebelión de las Cañadas ${ }^{4}$ el pasado se construye a partir de tres tipos de fuentes: documentales, orales y fotográficas..$^{5}$ Las fuentes que utiliza Carlos Tello Díaz valen por el tiempo narrado y se muestran como evidencia del haber-sido. La dimensión referencial del pasado adquiere entonces dicho estatus en tanto que lo ahí narrado, ampliamente reconocido o no, tiene un referente extra lingüístico, es decir, ha sucedido fuera del texto. Por lo tanto, sea o no reconocido por una comunidad histórica, al menos el lector debe asumir que tiene ante los ojos un hecho cierto pues, como lector de textos historiográficos, cree en lo que dice el historiador gracias al pacto de lectura que hace al asumirse como tal, y a las huellas que le son presentadas como evidencia.

En el "Prólogo", Carlos Tello Díaz explica la procedencia de las huellas que toman el lugar del pasado: 
Las fuentes de información que nutrieron este trabajo son muy variadas. Sin duda las más importantes fueron las testimoniales (...) Entre las personas que me dieron su testimonio "campesinos, asesores, sacerdotes, ganaderos, soldados, guerrilleros, funcionarios, activistas, investigadores", quiero destacar, por su importancia, a los indígenas ex zapatistas de las Cañadas. Las entrevistas que tuve con ellos constituyen el fundamento del libro. Algunos de los más conocidos figuran con su nombre de verdad, como Lázaro Hernández, líder por un tiempo del grupo Slop, y Santiago Lorenzo, presidente por unos meses de la Unión de Uniones. Los demás están protegidos por el anonimato (Tello, 2006: 10).

\section{Más adelante:}

El libro tiene, desde luego, muchas otras fuentes, además de las testimoniales. Me parece pueden ser ordenadas en tres grupos: las bibliográficas (libros, tesis, artículos), las hemerográficas (revistas, periódicos) y las documentales (manuscritos, estatutos, panfletos, comunicados, fotos y deposiciones "o declaraciones"). Todas ellas están enlistadas al final del libro, o bien a veces en las notas del texto. Estas notas desempeñan varias funciones. En unos casos las utilizo para comentar la procedencia de los documentos que llegaron a mis manos, así como también su credibilidad (...) Las notas sirven, además, para señalar los nombres (muy pocos) que fueron modificados en el libro (Tello, 2006: 10).

La explicación de las fuentes sugiere al menos dos interpretaciones. La primera de ellas se refiere al pacto de lectura que establece el lector. Los lectores de ficción como los de historiografía asumen que el tiempo narrado sucedió del modo como aparece en ambos tipos de relatos. En el primero de ellos, el como si, es decir, el modo en que se construye la historia, pide creer situaciones ocurridas en las dimensiones referencial y autorreferencial del pasado. El como si en los relatos historiográficos acentúa su credibilidad gracias a la evidencia. Las evidencias aseguran, al menos al lector, que lo dicho pertenece al haber-sido, es decir, al pasado tanto del autor/narrador como del lector. En la ficción histórica pura, o relato historiográfico, la huella realiza sus pretensiones de verdad.

La segunda interpretación se refiere a la función de lugartenencia de la huella con respecto al pasado. A partir de los testimonios orales y de las fuentes documentales, el autor/narrador re-construye el haber-sido. No existe una duplicación del pasado, sino más bien una re-construcción que está condicionada por los vestigios del pasado. El haber-sido del relato, entonces, toma un rumbo distinto del haber-sido del tiempo vivido, rumbo que configura el autor/narrador. Entonces, la representación del pasado no es efectiva, pues no existe una duplicación del mismo. Lo que se lee como si hubiera sucedido adquiere el matiz de representancia al no duplicar tal cual lo acaecido. El proceso de reconstrucción tendrá el carácter de imaginario a partir de la interpretación que de las huellas haga el historiador. El historiador se figura el mundo que produjo la huella. Figurarse que es la reconstrucción del haber-sido, reconstrucción condicionada por lo que la huella le pueda decir. ${ }^{6}$

\section{Figurarse el pasado del EZLN}

Ese haber-sido en el relato, condicionado por las huellas, convertido en un como si, se presenta en La rebelión de las Cañadas como la gestación del Ejército Zapatista de Liberación Nacional. El relato comienza con la crónica del primer día de guerra en 1994: "El l de enero de 1994, antes de clarear el alba, el Ejército Zapatista de Liberación Nacional entraba por las calles de San Cristóbal de Las Casas" (Tello, 2006: 15). La información anterior no necesita una cita en tanto que es un pasado claramente reconocido. Conforme avanza el relato aparecen las fuentes, entremezclando 
las orales con las documentales. "La toma (de la ciudad de San Cristóbal) fue, en verdad, 'un poema', como diría con humor el hombre que la comandaba" (Tello, 2006: 16). Las huellas que siguió Carlos Tello para la reconstrucción de lo ocurrido el 1 de enero, y los primeros días del levantamiento, son documentales y están basadas en las notas que produjo la prensa. Así lo constata la primera cita, la que califica a la toma de San Cristóbal como un poema, y así lo enfatiza el autor en esa primera nota al pie de página. ${ }^{7}$ Asimismo, desde la crónica, señala también la importancia de las evidencias que recoge en entrevistas, mismas que también valen por el haber-sido. Nos encontramos, pues, ante un relato cuyo estatus podría llamarse cuasi ficción en tanto que lo narrado es cuasi pasado. Es así porque al poner en relato los acontecimientos realmente el lector está ante la cuasi presencia de ellos. Es decir, los acontecimientos aparecen ante los ojos del lector gracias a las huellas o vestigios. En el caso que nos ocupa los acontecimientos se ven a partir de las fuentes documentales y orales a las que acudió el autor.

Por ejemplo, el testimonio de una turista en San Cristóbal, quien relata las primeras situaciones públicas del subcomandante Marcos:

(Marcos) era carismático y misterioso, aunque a muchos, aterrados, les pareció siniestro. Una turista lo miró con inquietud:

—iNos van a dejar ir? — preguntó.

Los turistas habían sido ya notificados que podrían regresar a sus hogares el 2 de enero.

— ¿Por qué se quieren ir? —contestó con ironía el hombre del pasamontañas-. Disfruten de la ciudad (Tello, 2006: 18).

Si pensamos que el estatus ontológico del pasado está condicionado por la función de lugartenencia de las fuentes, así como por modalidades de ficción porque el historiador se imagina el mundo que produjo la huella, podemos decir, a partir de la cita anterior, que
Carlos Tello Díaz se figura que lo sucedido, apoyado en su fuente, ocurrió como lo ha dicho. Este figurarse que, vale decir, convierte al autor en narrador omnisciente; el historiador imita al novelista al usar un narrador omnisciente y decir que Marcos había parecido carismático a algunos y siniestro a otros. Lo anterior se deduce debido a que la huella que vale por el pasado solamente indica el diálogo entre Marcos y los turistas, y no necesariamente los sentimientos que despertó en ellos. Al asumir posturas posmodernas "radicales", como la antirrepresentacionalista y antiesencialista (Jenkins, 2006), podemos sugerir que La rebelión de las Cañadas participa, aun sin quererlo, de la condición de la filosofía posmoderna al menos en el nivel de las licencias de su autor para "imaginarse" de manera epidérmica el surgimiento del EZLN. Es de manera epidérmica porque, utilizando los términos de White (2005), hay otra manera, mucho más profunda, de "imaginarse" el pasado, es decir, como un proceso metahistórico.

La imaginación surgida a partir de la interpretación de las fuentes está salpicada, en el texto, de varios efectos de ficción, como la descripción minuciosa de detalles que, seguramente, pudieron formar parte del haber-sido. El efecto de ficción, al que se volverá más adelante, en este caso exige, de nueva cuenta, el pacto del lector para creer en lo que el historiador afirma. El convencimiento se logra con la referencia explícita a la fuente que conduce al pasado, y cuyo pasado cede lugar. Lo anterior puede verse en la siguiente cita:

Después intervino Marcos. Su forma de ser "amable, muy suave” inspiraba confianza en la gente, que seguía con atención el sentido de su discurso. Muchos lo veían allí por vez primera, joven, bastante pálido, enflaquecido por los rigores de la montaña. Parecía muy convencido de lo que decía. Habló sobre el EZLN, sobre la necesidad de luchar por medio de las armas para terminar de raíz con la pobreza de México. Era indispensable, explicaba, "iniciar la 
ofensiva guerrillera contra el ejército burgués". Había que construir una nueva Patria (Tello, 2006: 114-115).

La descripción física del subcomandante Marcos exige, como se ha dicho, la posición del lector para creer en un pasado que, en este punto ciego, se reconstruye con la imaginación del historiador. Así, éste se figura cómo se produjo la huella del pasado. Inmediatamente después, aparece la frase entrecomillada "iniciar la ofensiva guerrillera contra el ejército burgués". La frase indica, junto con un número volado, la huella de ese pasado. El documento que se cita como huella es un texto del subcomandante Marcos publicado en la revista Nepantla, el órgano de difusión de las Fuerzas de Liberación Nacional. En él se informa de una reunión en la localidad Las Tazas entre integrantes del EZLN y sus habitantes, cuya finalidad era buscar la alianza entre el Ejército Zapatista de Liberación Nacional y las localidades que después se declararían zapatistas. Dicha reunión es imaginada por el historiador, como ha quedado dicho, lo que indica el proceso de figurarse el mundo que produjo la fuente.

La función de lugartenencia de la fuente, que realiza las pretensiones de verdad del relato historiográfico, a veces parece quedar en el olvido en La rebelión de las Cañadas. En el "Prólogo", al explicar la procedencia de sus fuentes, Tello señala la importancia de las orales, al proporcionarles éstas gran parte de la información, mismas que "constituyen el fundamento del libro" (Tello, 2006: 10). Queda sugerido, entonces, que mucho de lo que se dice en el texto proviene de las entrevistas que le proporcionaron indígenas zapatistas, activistas, sacerdotes, guerrilleros, soldados, campesinos y asesores. Muchos de ellos, zapatistas indígenas, no son llamados por sus nombres verdaderos, con tal de proteger su integridad, sobre todo de aquellos que entraron en conflicto en sus localidades y que fueron expulsados por no comulgar con la opción por las armas. De este modo, a lo largo del relato se encuentran pasajes que incluyen información, pero no siempre aparece una referencia explícita que conecte directamente el pasado del relato con el haber-sido. La explicación del uso de sus fuentes quizá pretenda, al mismo tiempo, zanjar la problemática de su uso a lo largo del texto.

Por ejemplo:

El contacto de la guerrilla con las comunidades fue, en un principio, el cuadro más importante que tenía la diócesis en las Cañadas. Su nombre era Lázaro Hernández. En aquel otoño de 1985, Lázaro, tzeltal como la mayoría de los habitantes de la región, estaba a punto de cumplir treinta y tres años, la edad de Cristo. Había nacido, como sus padres, como sus abuelos, en San Antonio las Delicias. A los doce años salió de su comunidad para cursar sus estudios con los maristas en San Cristóbal de Las Casas. Allí aprendió a leer y escribir, y también a conocer la Biblia. Trabajó con otros catequistas en el Congreso Indígena de Chiapas, como parte del equipo que coordinaba la parroquia de Ocosingo. Eran muy estrechas las relaciones con la Iglesia. Recibió de Samuel Ruiz el cargo de tuhunel y, a fines de los setenta, el cargo de tuhunel de tuhuneles, entonces el más prestigioso que daba la diócesis a los indígenas de las Cañadas (...) En 1985 (cuando se había relacionado con las Fuerzas de Liberación Nacional), casi todos eran ya, para él, figuras más o menos familiares. Había conocido a Marcos, un año atrás, en la reunión de Las Tazas, y había conocido también, con anterioridad, a la comandante Elisa, en una de las casas de seguridad que los rebeldes tenían en Tuxtla (Tello, 2006:.118-119).

En la cita se ve cómo se introduce a uno de los personajes principales en la historia del EZLN: Lázaro Hernández. Resume en dos páginas la biografía de Lázaro Hernández, dirigente de la Quiptic, catequista, y a la postre una de las fuentes de las que se sirvió el Estado mexicano para recoger información sobre el EZLN. En las páginas donde se cuenta la vida de Lázaro Hernández no hay ningún indicio de fuente, de 
documento, que tome el lugar del haber-sido. La fuente inmediata aparece una página después en una situación concreta: el encuentro del subcomandante Marcos con habitantes del ejido San Francisco, a quienes les propuso la guerrilla. De hecho, en dicho encuentro Lázaro Hernández jugó un papel importante para introducirlo en la localidad. La biografía, breve, que se hace de Lázaro Hernández carece de una fuente que cumpla la función de lugartenencia, que tome el lugar del haber-sido. La fuente que se menciona cumple dicha función para el encuentro del subcomandante Marcos con los indígenas de San Francisco. Esta función de lugartenencia la cumple con notas de prensa aparecidas en la revista Proceso, así como el diario de combate de Marcos. Situaciones como la anterior parecieran salvarse a la explicación de las fuentes que ya se ha mencionado, y en el caso concreto de los datos biográficos de Lázaro Hernández, la función de lugartenencia pudo haberse cumplido al advertir, en el mismo "Prólogo", que el fundamento del libro se halla en los relatos obtenidos de varios ex milicianos zapatistas, entre los que se encuentra, precisamente, Lázaro Hernández. Hecha la aclaración, mucho de lo que se dice se maneja ad líbitum.

En este sentido vale decir, de nueva cuenta, el pacto que establece el lector implicado con el narrador/autor. Dicho pacto se establece al saber que el relato que se lee tiene pretensiones de verdad, y que su autor es un historiador que persigue la verdad. En este sentido, el libro puede leerse como si fuera una novela. Pero el como si quiere decir que es mera apariencia, porque en realidad el lector está ante una obra distinta a la novela. Si volvemos algunas líneas de la cita anterior, como "En aquel otoño de 1985, Lázaro, tzeltal como la mayoría de los habitantes de la región, estaba a punto de cumplir treinta y tres años, la edad de Cristo. Había nacido, como sus padres, como sus abuelos, en San Antonio las Delicias", nos encontramos ante un texto que bien vale como literario o novelado, pero que tiene pretensiones de verdad, y que, como se ha dicho, éstas se realizan gracias a la función de lugartenencia de la fuente, la que indica que el relato historiográfico, a diferencia del literario, está conectado al haber-sido por referencia indirecta. Pero al fin conectado.

Además, debido a que el historiador imita al novelista al asumir que el narrador, a la vez autor, es omnisciente, se realiza la postura de la filosofía posmoderna que entiende al texto historiográfico como artefacto literario en su modalidad narrativa. Es cierto que la corriente historiográfica emparentada con los Anales, representada por Fernando Braudel, y conocida como tercera generación de esta "escuela" francesa, ha eclipsado la narración como característica inherente a la historiografía. Sin embargo, como lo ha hecho notar Ricoeur, la historiografía siempre ha estado ligada, a pesar de Braudel, a la narrativa (2004: 169-193). Ricoeur piensa en la construcción de cuasi personajes, o entidades de primer orden (Vergara, 2006: 60-63), lo que equipara a la historia de las estructuras con la historia de los acontecimientos. Estos cuasi personajes son construcciones del historiador, sobre todo del apegado a la corriente braudeliana, quien narra, por ejemplo, el desarrollo de las clases sociales; el gran personaje de Braudel es el mar Mediterráneo. Una de las ideas de la narratividad en la historia que se aviene a la característica del narrador omnisciente en La rebelión de las Cañadas, es lo que se ha llamado frase narrativa. Ésta, que Ricoeur toma de Arthur Danto, sugiere que en toda narración se conocen las acciones y las consecuencias de las acciones, es decir, el principio y el final de la historia. La frase narrativa "es una de las descripciones posibles de una acción en función de aquellos acontecimientos posteriores que desconocían los agentes y que, en la actualidad, conoce el historiador" (Ricoeur, 1999: 90). En este sentido, ¿cómo puede Carlos Tello Díaz decir que en el momento del diálogo de Marcos con los turistas, en la plaza de San Cristóbal el primero de enero, a éstos les pareció siniestro? Como la fuente que cita no explicita "lo siniestro", es posible decir que es un juicio que se formuló con el paso del tiempo, y no en 
el momento de lo relatado. ¿Cómo puede saber que Lázaro Hernández resultó ser, sólo al principio, uno de los contactos más importantes de la guerrilla con las localidades? ¿Cómo sabe que sólo al principio y no durante todo el trayecto del EZLN? Es decir, como narrador omnisciente, Tello conoce las acciones posteriores, y los juicios al respecto, que una acción ocasionó en el pasado. Consecuencias y juicios que los agentes de la acción, tanto en el tiempo vivido como en el narrado, no conocían. Quizá este otro ejemplo ilustre mejor la cuestión de la frase narrativa:

\section{A lo largo de 1984 empezó a destacar sobre los demás uno de los cuadros mejor preparados de las FLN, uno que con el curso de los años habría de pasar a la historia con un nombre de leyenda: Marcos. Su nombre de verdad, en el movimiento, lo conocía nada más la Dirección Nacional. Rafael Guillén, en aquel verano, acababa de cumplir veintisiete años... (Tello, 2006: 12).}

Para el año en que sitúa la narración, 1984, no se conocía públicamente el verdadero nombre del subcomandante Marcos. Se dio a conocer hasta el año 1995, el mismo en que se publicó la primera versión de La rebelión de las Cañadas. Todo el libro, aún más, está pensado como una gran frase narrativa. Comienza con la crónica de los primeros días de 1994 y cierra con el mismo acontecimiento. Al ser así se anticipa al desenlace de la conformación del EZLN. Es decir, el pasado que se narra es el de la clandestinidad de los neozapatistas, y se sabe siempre, desde el principio del relato, cuál será el final del mismo. Esta es una de las características de la narrativa literaria, en la que el narrador, al asumirse como omnisciente, sabe cuáles son las consecuencias de las acciones que ha de narrar, y se anticipa a ellas en el relato, en el nivel de la configuración. En este sentido opera también la distinción que propone Hayden White entre crónica y relato. La crónica será el registro de hechos sin distinción entre principio y final, y su registro puede ser de manera indefinida o hasta que el cronista lo decida (White, 2005: 17). Entonces, en cuanto registro que sigue un desarrollo cronológico lineal, el cronista no conoce el desenlace de los hechos en tanto que le son contemporáneos. La crónica, sin embargo, adquiere el estatus de relato porque el historiador conoce el principio y el final de los acontecimientos que registra, es decir, "las inauguraciones y terminaciones (provisionales) de procesos sociales y culturales" (White, 2005: 17).

La modalidad de ficción en la ficción histórica pura, que cuestiona la realidad del pasado histórico, adquiere, pues, un matiz en La rebelión de las Cañadas. La lugartenencia no funciona siempre en el relato cuando no se explicitan las fuentes, aunque se sugiera que el pasado del relato está conectado con el haber-sido por las fuentes orales.

\section{Notas}

' El artículo es un extracto, con modificaciones, de la tesis de mi autoría El reino de la intriga. La construcción del pasado en ficciones históricas sobre el Ejército Zapatista de Liberación Nacional.

${ }^{2}$ Para un acercamiento a la filosofía posmoderna de la Historia, véase: Jenkins, 2006 y Morales, 2005.

${ }^{3}$ La filosofía posmoderna de la historia, valga la aclaración, cuestiona el concepto de verdad al sostener, algunos de sus representantes, que el pasado no se puede conocer tal como ocurrió. El cuestionamiento a la verdad vuelve a ponerse en el centro de la discusión con la aparición de lo que se ha llamado "giro lingüístico", que cuestiona la relación entre conocimiento y realidad. En pocas palabras, de acuerdo con Rorty, es el lenguaje el medio que representa la realidad. (Rorty, 1990: 164). El lenguaje, entonces, sustituye a la experiencia. Las consecuencias del giro lingüistico en la historiografía devienen cuestionamientos a la representación histórica y al concepto de verdad en la historia.

${ }^{4}$ Considero historiográfico el libro de Tello al considerar en él sus pretensiones de verdad. 
${ }^{5}$ No es menester mío criticar la procedencia de las fuentes de La rebelión de las Cañadas. Se ha dicho, por ejemplo, que Carlos Tello Díaz escribió una suerte de reporte policíaco, y que sus fuentes fueron proporcionadas por el Estado mexicano antes de que algún otro investigador del fenómeno zapatista tuviera acceso a ellas. Asimismo, se ha dudado de que haya entrevistado, como él afirma, a milicianos zapatistas en sus comunidades. Se sugiere, entonces, que la información fue obtenida como producto de delaciones de ex militantes zapatistas, lo que levantó comentarios a favor y en contra del libro. Véase Ramón Martínez de Velasco, "Los infiltrados" en www. libertaddepalabra.com/2007/03/los-infiltrados; José Gil Olmos, "Tello, la desconfianza", en http://www. cs.uwaterloo.ca/-alopez-o/politics/rebelion.html; José Gil Olmos, "El desmentido", en www.proceso.com. mx/ analisis_int.html?an=48733; Aurelio Asiain, "La rebelión de las Cañadas", en www.letraslibres.com/ pdf.php?id=4625.

${ }^{6}$ No significa, a juicio propio, la misma operación que defiende Ranke cuando supone que se reconstruye, gracias a los documentos, la realidad del pasado tal como ocurrió. Véase Corcuera, 2002: 123-140.

7 "El relato de los hechos que sucedieron en Chiapas a principios de 1994 está basado en la cobertura de la prensa, así como también en el testimonio de personas que presenciaron los hechos: turistas, reporteros, paseantes, soldados y misioneros de la diócesis de San Cristóbal", nota l del capítulo l "El éxodo", p. 16.

\section{Bibliografía}

Asiain, Aurelio (2009), “La rebelión de las Cañadas”, en www. letraslibres.com/pdf.php?id=4625, [junio de 2009].

Corcuera de Mancera, Sonia (2002), Voces y silencios en la historia. Siglos XIX y XX, México: Fondo de Cultura Económica.
Jenkins, Keith (2006 (1999, inglés), ¿Por qué la historia? Ética y posmodernidad, México: Fondo de Cultura Económica.

Lacapra, Dominick (2005), "Escritura de la historia, escritura del trauma”, en Luis Morales Moreno, Gerardo (comp.), Historia de la historiografía contemporánea (de 1968 a nuestros días), México: Instituto de Investigaciones Dr. José María Luis Mora, pp. $443-$ 490.

Martínez de Velasco, Ramón (2009), “Los infiltrados”, en www.libertaddepalabra.com/2007/03/los-infiltrados, [junio de 2009].

Morales Moreno, Luis Gerardo (comp.) (2005), Historia de la historiografía contemporánea (de 1968 a nuestros días), México: Instituto Mora.

Olmos, José Gil (2009), “Tello, la desconfianza”, en http:// www.cs.uwaterloo.ca/-alopez-o/politics/rebelion. html, [septiembre de 2009].

Olmos, José Gil (2009), "El desmentido", en www. proceso.com.mx/analisis_int.html?an=48733, [septiembre de 2009].

Ricoeur, Paul (1999), Historia y narratividad, Barcelona, España: Paidós.

Ricoeur, Paul (2004), Tiempo y narración. Configuración del tiempo en el relato histórico, vol. I, (1985, 1르 francés), México: Siglo XXI.

Ricoeur, Paul (2006), Tiempo y narración. El tiempo narrado, vol. III, (1985, 1a francés), México: Siglo XXI.

Rorty, Richard (1990), El giro lingüistico. Dificultades metafilosóficas de la filosofía lingüística, España: Paidós y Universidad Autónoma de Barcelona.

Tello Díaz, Carlos (2006), La rebelión de las Cañadas. Origen $y$ ascenso del EZLN, México: Planeta.

Vergara, Luis (2006), Paul Ricoeur para historiadores. Un manual de operaciones, México: Universidad Iberoamericana y Plaza y Valdés.

White, Hayden (2005 (1973, inglés), Metahistoria. La imaginación histórica en la Europa del siglo XIX, México: Fondo de Cultura Económica. 